\title{
INTERVENÇÃo No ESPAÇO Público: O CASO DA PRAÇA JOÃO PESSOA/PB
}

\section{Intervention In Public Space: The Case Of João Pessoa Square}

\author{
Maria da Conceição Pereira Paulino \\ Universidade Federal da Paraíba \\ cecita.jp@gmail.com
}

\section{Resumo}

A Praça João Pessoa é um dos espaços livres públicos mais antigos da cidade homônima, capital do estado da Paraíba. Esta praça evoluiu a partir do Terreiro da Capela Jesuítica do século XVI, espaço de uso para festas religiosas e procissões. Com a expulsão dos jesuítas, o conjunto arquitetônico formado pela Igreja e Seminário ficou sendo local de moradia dos Capitães Mores. Posteriormente, em 1771, dos Presidentes da Província da Parahyba (conhecido como O Largo do Palácio), que além do uso religioso, passou ser o espaço principal das festividades do poder. Em fins do século XIX este espaço foi transformado em Jardim Público e passou a ser o principal espaço de sociabilidade e lazer da cidade com realização de retretas aos fins de semana. Em 1933, este espaço foi transformado em "Lugar de Memória" para a Revolução de 1930. Nela, diante do monumento "Altar da Pátria" se realizavam cultos à imagem do mitificado, sagrado e heroicizado João Pessoa. Neste artigo apresento como se processou esta intervenção. Inicio com uma discussão do conturbado governo de João Pessoa em meio ao conflito armado que ficou conhecido como Guerra de Princesa e abordo as motivações políticas para a criação da Praça em sua homenagem, após seu assassinato.

\section{Palavras-chave}

João Pessoa (cidade, política e praça), Lugar de Memória, Intervenção Urbana

\section{Abstract}

João Pessoa Square is one of the oldest public open spaces of the homonymous city, the capital of the state of Paraíba - Brazil. This square has expanded from Terreiro da Capela Jesuítica of the sixteenth century, a space used for religious festivals and processions. The architectural ensemble, consisting of a church and a seminary, which served as seat for the Jesuit order has, with the expulsion of the Society of Jesus, turned into housing for the Major Captains. Later, in 1771, the place was turned into 
housing for the Presidents of the Province of Parahyba (former name), hosting both religious ceremonies and festivities of the Power. At the end of the nineteenth century, that area was given status of Public Garden and it became the main place for sociability and entertainment with performing band concerts on weekends. In 1933, the became "Place of Memory" on account of the Revolution of 1930, a coup that ousted the president. There, the adoration of the mythologized, sacred and heroic character image of João Pessoa was held before the monument "Altar da Pátria". This article introduces how this intervention took place. It begins with a discussion about the troubled government of João Pessoa in the midst of an armed conflict that became known as Guerra da Princesa and, it also approaches the political motivations for the creation of the square in honor of the governor after his assassination.

\section{Keywords}

João Pessoa (city, politics and square), Place of Memory, Urban Intervention

\section{Introdução}

A história de uma cidade está contida dentro das memórias dos seus lugares e dos elementos urbanos que melhor revelam as sociabilidades vividas. Nesse contextoas praças ocupam posição de destaque. Como destaca Colchete Filho (2008 p.32) "vista no conjunto de espaços da cidade, a praça reúne elementos históricos e formais que a designam como um dos espaços mais importantes do meio urbano". Nas cidades brasileiras ou de origens portuguesas, a praça surgiu de forma marcante e típica diante de capelas, igrejas, conventos, tal como destacou Murilo Marx.

A praça como tal, para reunião de gente e para exercício de um sem-número de atividades diferentes, surgiu entre nós, de maneira marcante e típica, diante de capelas ou igrejas, de conventos ou irmandades religiosas. Destacava, aqui e ali, na paisagem urbana estes estabelecimentos de prestígio social. Realçava-Ihes os edifícios; acolhia os seus frequentadores. (MARX, 1980, p. 50)

No Renascimento europeu as praças se converteram em elemento urbano de transformação e embelezamento das cidades e passaram a ter mais do que um valor funcional, pela incorporação de valor político-social, além de valor simbólico e artístico, não só realçavam os edifícios, mas passaram a ser realçadas por eles. (DE ANGELIS, etal. 2004, p.58). Para Robba e Macedo (2003, p.17) as praças são: URBANA, V.6, no 9, ago-dez, 2014 - Dossiê: Dimensões Simbólicas das Intervenções Urbanas CIEC/UNICAMP 
"Espaços livres públicos urbanos destinados ao lazer e ao convívio da população, acessíveis aos cidadãos e livres de veículos, definidos pela malha urbana formal e que não ocupem mais de duas ou três quadras consecutivas."

As reformas urbanas realizadas em diversas cidades brasileiras, no início do século $X X$, incidiram diretamente na morfologia urbana com aberturas e alargamentos de ruas e praças, instalação de serviços como água e energia, calçamentos, alinhamento das edificações e novas construções. Tudo congregado para o surgimento de um novo cenário urbano, um cenário moderno. Mesmo diante de tantas demolições e construções muitas praças sugiram, outras desapareceram, contudo algumas permaneceram em nossas cidades.

Neste artigo, que é resultado de minha dissertação de mestrado, abordarei uma praça que tem uma longa duração dentro da capital da Paraíba, mais precisamente abordarei a intervenção urbana e simbólica realizada na Praça João Pessoa. Situada no antigo sítio de fundação da cidade e na área tombada pelo Instituto do Patrimônio Histórico e Artístico Nacional (IPHAN), esta praça é muito significativa para a história política e urbana da cidade de João Pessoa. Originada a partir doTerreiro fronteiro à Igreja Jesuítica do século XVI, se conformou em Largo do Palácio dos Governadores no século XVIII, em Jardim Públicono século XIX, depois em Praça Comendador Felizardono início do século XX. Em 1930 passa a se chamar Praça João Pessoa, quando passou a ser um "lugar de memória" para o mártir da "Revolução de 1930"1.

\section{João Pessoa: o político e seus "lugares de memória"}

A imagem de herói criada para João Pessoa começou no plano paraibano, ou seja, no contexto politico interno, no combate à Guerra de Princesa. Confronto armado travado entre o governo do estado da Paraíba e o coronel da cidade de Princesa, situada no sertão paraibano.Este conflito assumiu tal proporção que o coronel José Pereira da cidade de Princesa decretou a independência do município em junho de 1930, denominando-o Território Livre de Princesa. Diante disso, João Pessoa passou a se promover e ser bradado como o herói que lutava para restituir a

\footnotetext{
${ }^{1}$ Fato que marcou historicamente o fim da Primeira República no Brasil, a Revolução de 1930 foi um movimento desencadeado após o assassinato do Presidente do Estado da Paraíba João Pessoa, vice de Getúlio Vargas para a disputa presidencial. A revolução conduziu Vargas à Presidência do Brasil, por meio de um golpe que impediu a posse do presidente eleito Júlio Prestes. Sobre esse assunto há uma vasta produção, destaco FAUSTO, Boris. A Revolução de 1930: historiografia e história. 7 ed. São Paulo: Brasiliense, 1981.

URBANA, V.6, no 9, ago-dez, 2014 - Dossiê: Dimensões Simbólicas das Intervenções Urbanas CIEC/UNICAMP
} 
integridade do Estado da Paraíba. O conflito só se encerrou com seu assassinato em 26 de julho de 1930 e com a intervenção do presidente do Brasil, Washington Luiz, em agosto do mesmo ano ${ }^{2}$.

Com o mártir, as homenagens póstumas vieram sacramentar o mito, seu nome foi dado a diversos logradouros, não só aqui, mais em diversas cidades do Brasil. ${ }^{3} \mathrm{O}$ caso da Praça João Pessoa, aqui abordado, completou esse ciclo de mitificação quando em 1933 se instalou no então Jardim Público, um monumento denominado Altar da Pátria.Tal intervenção fez do local um espaço de culto político à imagem de João Pessoa, transformando-se num "lugar de memória". O historiador Francês Pierre Nora, teórico desse conceito, nos diz que estes são locais, ou quaisquer suportes de registro histórico-documental, material ou imaterial "simples e ambíguos, naturais e artificiais" que transmitam lembrança de um fato passado. Contudo, para ser considerado lugar de memória, o mesmo deve estar investido de uma aura simbólica, ser objeto de um ritual e ter a funcionalidade de lembrar um fato ou algo. O autor ainda nos diz que

[...] os lugares de memória nascem e vivem do sentimento que não há memória espontânea, que é preciso criar arquivos, que é preciso manter aniversários, organizar celebrações, pronunciar elogios fúnebres, notariar atas, porque essas operações não são naturais (NORA, 1993, p. 10) ${ }^{4}$

Ou seja, a criação da Praça João Pessoa se encaixa perfeitamente nessa acepção, pois foi uma criação intencional e deliberada, tal como revelam as cerimônias e ritos realizados em seu espaço. Em 1931, o primeiro ano após a morte

\footnotetext{
${ }^{2}$ Sobre esse assunto consultar: RODRIGUES, Inês Caminha Lopes. A Revolta de Princesa: Uma contribuição ao estudo do Mandonismo Local - Paraíba (1930) João Pessoa: A União, 1978 e MARIANO, Serioja R.Cordeiro.Signos em confronto?: O arcaico e o moderno na cidade de Princesa (PB) na década de 1920. João Pessoa: Editora Universitária da UFPB, 2010.

${ }^{3}$ Como bem observou Aires existem treze avenidas, vinte e seis ruas, quatro travessas, um largo e mais duas praças levam o nome de João Pessoa, em dezoito capitais brasileiras, além de outras ocorrências em demais municípios de alguns estados.

4 "São lugares com efeito nos três sentidos da palavra, material, simbólico e funcional, simultaneamente ou em graus diversos. Mesmo um lugar de aparência puramente material, como um depósito de arquivos, só é lugar de memória se a imaginação o investe de uma aura simbólica. Mesmo um lugar puramente funcional, como um manual de aula, um testamento, uma associação de antigos combatentes, só entra na categoria se for objeto de um ritual. Mesmo um minuto de silêncio, que parece o exemplo extremo de uma significação simbólica, é ao mesmo tempo o recorte material de uma unidade temporal e serve, periodicamente, para uma chamada concentrada de lembrança. Os três aspectos coexistem sempre". (p. 21-22).NORA, Pierre. Entre Memória e História: a problematica dos lugares. In: Projeto História. n. 10. 1993. A presença destes aspectos na Praça João Pessoa foi observada no trabalho do historiador Luciano AIRES, intitulado Inventando Tradições, Construindo Memórias: A "Revolução de 1930" na Paraíba. Dissertação (Mestrado em História) Programa de Pós-Graduação em História. Universidade Federal da Paraíba. João Pessoa; UFPB, 2006.

URBANA, V.6, no 9, ago-dez, 2014 - Dossiê: Dimensões Simbólicas das Intervenções Urbanas CIEC/UNICAMP
} 
de João Pessoa, a programação de homenagens teve uma semana de duração, sendo cada um dos dias reservados a um determinado setor da sociedade.

Os estudantes, professores e diretores ficavam próximos ao Altar da Pátria, defronte à Escola normal, a fim de recepcionarem o interventor e sua comitiva oficial, que traziam a efígie de João Pessoa para colocá-la no referido altar. Os operários e trabalhadores, de um modo geral, partiam da Praça do Trabalho; as "classes armadas" tomavam como ponto de partida os quartéis; os comerciantes, por sua vez, saiam da Associação Comercial; o clero e Associações de Caridade reuniam-se na catedral; todos em direção ao Altar da Pátria, rumando ao encontro da efígie do mito João Pessoa e dos representantes do Estado que lá estavam. (AIRES, 2012, p. 88)

\section{De jardim Público à Praça João Pessoa}

A maior de todas as homenagens feitas a João Pessoa foi sem dúvida a mudança do nome da cidade, antes Cidade da Parahyba. Contudo, a modificação da praça ocupa um lugar de destaque, diante da intervenção arquitetônica que substituiu seu coreto por um monumento cheio de simbologia. Tal modificação se iniciou em maio de 1933, conforme destaca a notícia.

No decorrer desta semana deverá chegar a esta capital o monumento que a Parahyba vai erigir à memória do presidente João Pessoa, executado pelo escultor Humberto Cozzo, por encomenda do governo. As providências preliminares para o início da montagem da monumental obra de arte já estão sendo tomadas pelo Sr. Borja Peregrino, prefeito da capital. O pavilhão existente no centro da praça que tem o nome do grande cidadão está prestes a desaparecer, desmontado, para dar lugar ao assentamento da base da nova construção ${ }^{5}$

A última retreta foi realizada em 04 de junho de 1933 e a construção do monumento se iniciou no dia 10, quando foi assentada a pedra fundamental. A organização da solenidade foi especialmente elaborada pelo "Centro Cívico João Pessoa", que se reuniu para discutir "os meios de imprimir-se o maior brilho àquela cerimônia, que constituirá mais uma oportunidade de cultuar-se a memória do grande presidente e terá um cunho eminentemente popular" ${ }^{\prime 6}$.

\footnotetext{
${ }^{5}$ A União 25 de maio de 1933.

${ }^{6}$ A União 31 de maio de 1933.

URBANA, V.6, no 9, ago-dez, 2014 - Dossiê: Dimensões Simbólicas das Intervenções Urbanas CIEC/UNICAMP
} 


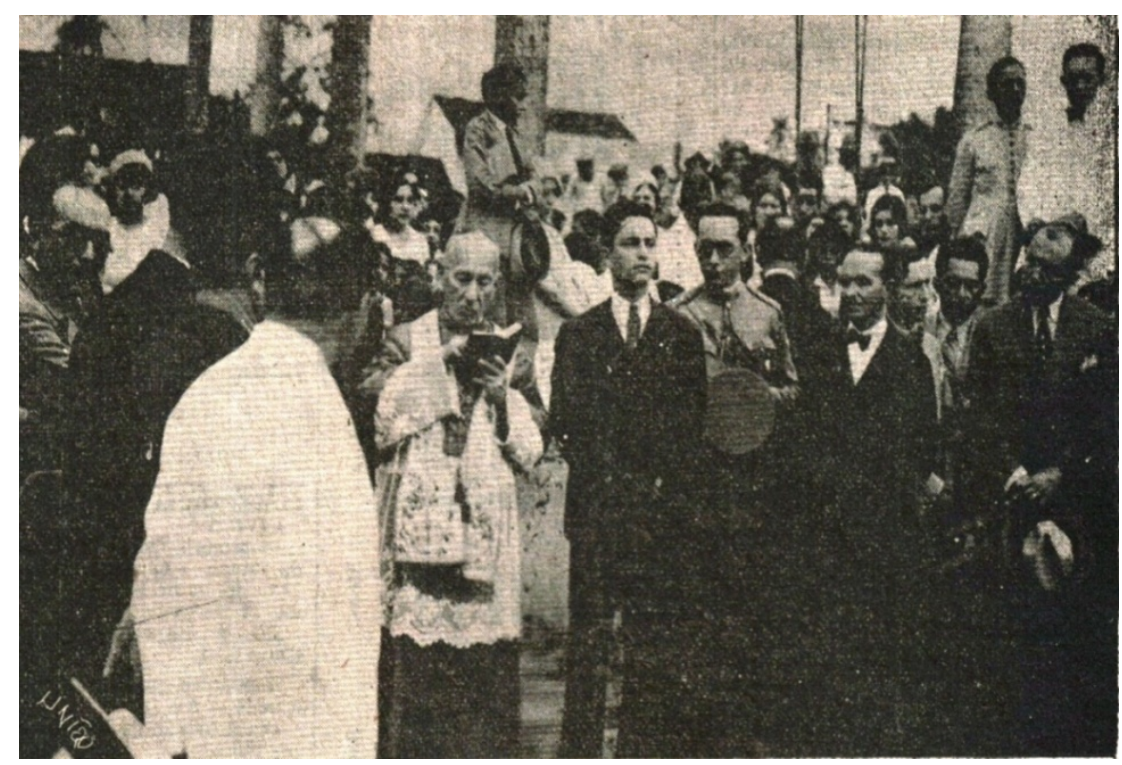

Figura1 - Benção da pedra fundamental.

Fonte: Jornal A União, 13 de junho de 1933.

$\mathrm{Na}$ imagem acima vemos o momento em que foram lançadas as bênçãos à pedra fundamental do monumento pelo arcebispo D. Adauto Aurélio de Miranda Henriques. Percebemos nas autoridades, políticos e gente da alta sociedade um ar de formalidade e tensão, o tom do discurso do Cônego Matias Freire, também é revelador nesse sentido.

Esta praça é um dos locaes sagrados pelo civismo parahybano. Porque está circumdado de fortalezas de nossa liberdade, de nosso pensamento, de nosso heroísmo, nas luctas maiores que temos ferido, até hoje, contra os erros de uma Republica sem republicanos. [...] Aqui viemos, senhores, para assistir ás primeiras fundações de um templo, que terá vida bem mais longa, bem mais expressiva, bem mais eloquente que nossa vida individual. Vamos ter aqui uma escola permanente e sempre aberta às gerações futuras para o ensino e a aprendizagem de um evangelho de salvação publica, para o culto da coragem [...] Os templos religiosos são destinados ao culto do' Deus Vivo e sacramentado e dos Santos de sua doutrina [...] Os monumentos civicos teem uma finalidade parecida, porquesão erigidos pelos povos ou pelos governos para o fim de celebrarem, perpetuamente, o culto á memoria dos grandes homens $[\ldots]^{7}$

A imagem a seguir (figura 2) mostra parte da cena do momento logo após o discurso, quando de forma ritualística coloca-se ao lado da pedra fundamental, uma caixa contendo alguns objetos pelo Interventor Gratuliano Brito.

7Jornal A União, 13 de junho de 1933.

URBANA, V.6, no 9, ago-dez, 2014 - Dossiê: Dimensões Simbólicas das Intervenções Urbanas CIEC/UNICAMP 
[...] desceram á fundação, onde o Chefe do Govêrno encerrou, no logar competente, a caixa de bronze, artisticamente cinzelada, que encerrava a acta da solennidade, uma collecção das moedas nacionaes em circulação, offerecida pelo dr. João Mauricio e prefeito Borja Peregrino, jornaes do dia, revistas do Rio de Janeiro, um exemplar do "Almanach do Estado da Parahyba" e uma copia do discurso do cónego Mathias Freire. [...] O chefe do Estado, dando como lançada a Primeira Pedra, joga-lhe com uma colher dourada um pouco de argamassa de cimento. A autoridade ecelesiastica dáIhe a bençam e, a seguir o côrode alumnas do Orphéon da Escola de Música "Anthenor Navarro", acompanhadas pelas creanças das escolas publicas, sob a batuta do maestro Gazzi de Sá canta o "Hymno João Pessoa", encerrandose o cerimonial. ${ }^{8}$

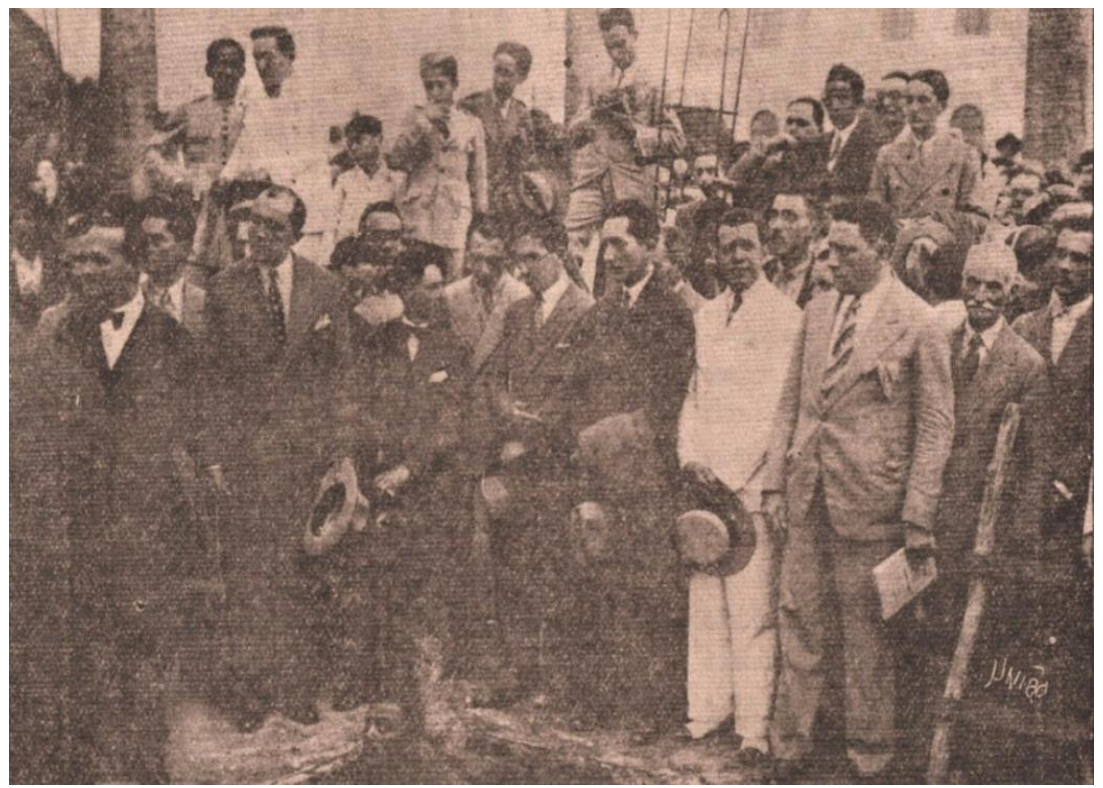

Figura 2 - Autoridades assistindo a colocação da pedra

Fonte: Jornal A União, 13 de junho de 1933.

A remodelação da praça seguiu os princípios modernistas divulgados em congressos e encontros disciplinares desde 1920 (CALDEIRA 2007 p. 287).A partir de 1930 arquitetos e urbanistas passaram a ser contratados para elaborar planos urbanos de remodelação e expansão de cidades. O arquiteto e urbanista, Nestor Egydio de Figueiredo, foi contratado para elaborar planos urbanos para o Recife, Campina Grande, Fortaleza e João Pessoa (MUNIZ 2006, p. 138) e dentre os projetos elaborados por sua equipe para a cidade foi o novo ajardinamento da Praça.

Não poderia, entretanto, permanecer a praça João Pessoa com a feição antiga, em linhas que destoavam, por completo, do estylo que presidiu à confecção da obra que hoje constitui o seu principal motivo. Elaborado um

${ }^{8} \mathrm{Ibd}, 1933$.

URBANA, V.6, no 9, ago-dez, 2014 - Dossiê: Dimensões Simbólicas das Intervenções Urbanas CIEC/UNICAMP 
projecto de jardim moderno pelo urbanista Nestor de Figueirêdo, acham-se concluídos os trabalhos de remodelação do melhor logradouro publico da capital, dotado de iluminação bastante e com aspecto inteiramente novo ${ }^{9}$

As modificações realizadas the deram as linhas modernas que modificaram os canteiros, antes quase todos sinuosos, que passaram a ser retilíneos, como podemos verificar nas imagens abaixo. No centro da praça(figura 3) está o coreto, rodeado por bancos e palmeiras imperiais. Este foi o segundo coreto instalado após uma grande reforma em 1913. Possuía cúpula arredondada, traços menos rígidos e foi assentado sobre maior elevação do solo, comparado ao anterior. Era sustentado por colunas e circulado por um peitoril. Várias foram as cidades brasileiras que fez uso da "arquitetura metalúrgica" europeia, com peças trazidas entre meados do século XIX e início do século XX. A Saracen Foundry de Walter MacFarlanes\&Co foi uma das fundições que mais importou para o Brasil. Suas peças em ferro fundido estão presentes no Pará, Manaus, São Paulo, Ceará e em Pernambuco (COSTA, 2001 p. 100). Não sabemos a procedência deste coreto, contudo notícias dos jornais da época falava que o mesmo havia sido importado da França, outro grande fabricante de mobiliários urbanos de ferro.

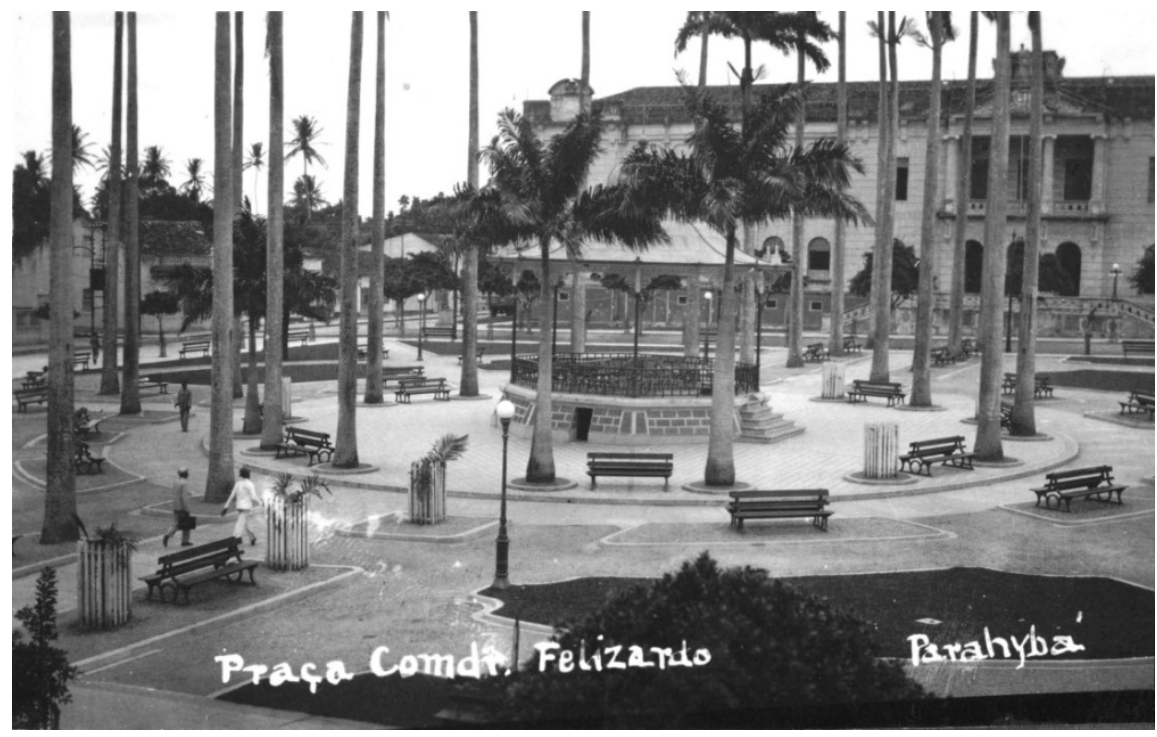

Figura 3 - Praça Comendador Felizardo, 1928.

Fonte: Stuckert Filho, 2004.

9 Exposição da Administração do Interventor Gratuliano Brito 1932 a 1934. Imprensa Oficial. João Pessoa. 1935.

URBANA, V.6, no 9, ago-dez, 2014 - Dossiê: Dimensões Simbólicas das Intervenções Urbanas CIEC/UNICAMP 
A planta da praça (figura 4) mostra como ficou seu novo, e ainda atual, traçado. Apesar das linhas mais retas, o passeio manteve a sua circularidade, mesmo com a nova disposição dos canteiros e bancos. As palmeiras imperiais permaneceram. A nova praça foi inaugurada no dia 08 setembro de 1933, com a presença do Presidente do Brasil, Getúlio Vargas, que a essa época visitava a região em campanha pela continuidade na presidência. Naquele momento, homenagear o herói de 1930, era uma oportunidade para se relembrar nacionalmente a "revolução" que o havia colocado no poder (AIRES, 2006, p. 63).

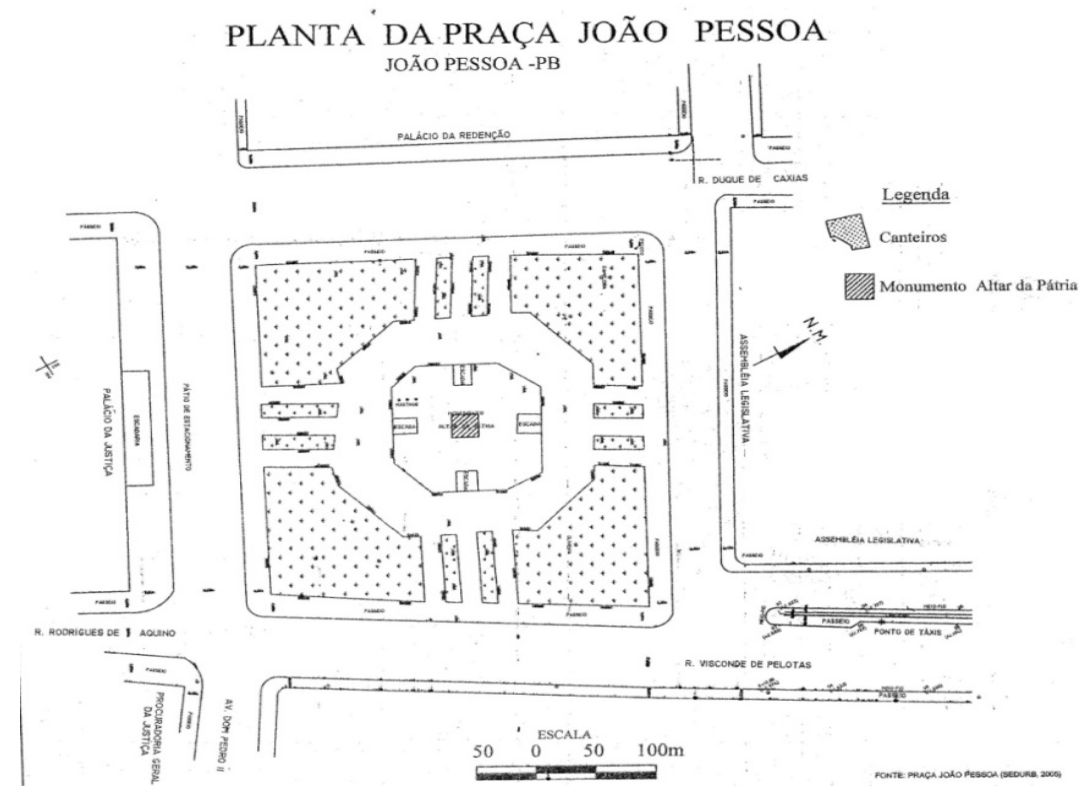

Figura 4 - Planta da Praça João Pessoa. SEDURB, 2005

Fonte: RAMOS, 2006

A solenidade de inauguração da praça durou um dia inteiro, com direito a acrobacias dos aviões da esquadrilha da Marinha de Guerra que acompanharam a excursão presidencial (AIRES, 2006, p. 64). O ministro José Américo de Almeida, chefe do Partido Progressista, fez o discurso oficial, em seguida, o filho de João Pessoa, Epitácio Pessoa Cavalcanti, falou em nome da família ao som do hino em homenagem a seu pai,entoado pelas alunas da Escola Normal. Getúlio Vargas e D. Adaucto descobriram o monumento (AIRES, 2006 p. 64). A descrição de Humberto Cozzo, artista que criou o monumento nos revela alguns pontos interessantes.

[...] iniciando-se por uma ampla base de 14 metros por 10, fazendo com que parte integrante da praça, elevase o monumento por uma harmonia de blocos sobrepostos à altura de 10 metros. Nas partes lateraes do monumento dois

URBANA, V.6, no 9, ago-dez, 2014 - Dossiê: Dimensões Simbólicas das Intervenções Urbanas CIEC/UNICAMP 
grupos grandiosos e symétricos como requer o conjunto, symbolizando em syntese, os dois traços culminantes da vida gloriosa do grande vulto que se vae homenagear: ACÇÃO e CIVISMO. O primeiro representado por duas figuras masculinas que sustentam em seus braços vigorosos uma bigorna, symbolo do trabalho e actividade, guiados pela figura alada do gênio. O outro, duas figuras determinadas de combatentes, dispostos à luta em defeza de seus ideaes, symbolizarão o "Civismo". Na parte superior do monumento uma figura enérgica empunhando a bandeira da Parahyba e o braço direito distendido em synal de protesto, symbolizarão a célebre phrase: Nego. $\mathrm{Na}$ parte anterior, em attitudes serena e natural, a estátua ao grande brasileiro, tendo em seus ombros, como complemento decorativo, a toga de magistrado. Nas extremidades lateraes da base, dois bancos que serão executados em granito, completa (sic.) o monumento. ${ }^{10}$

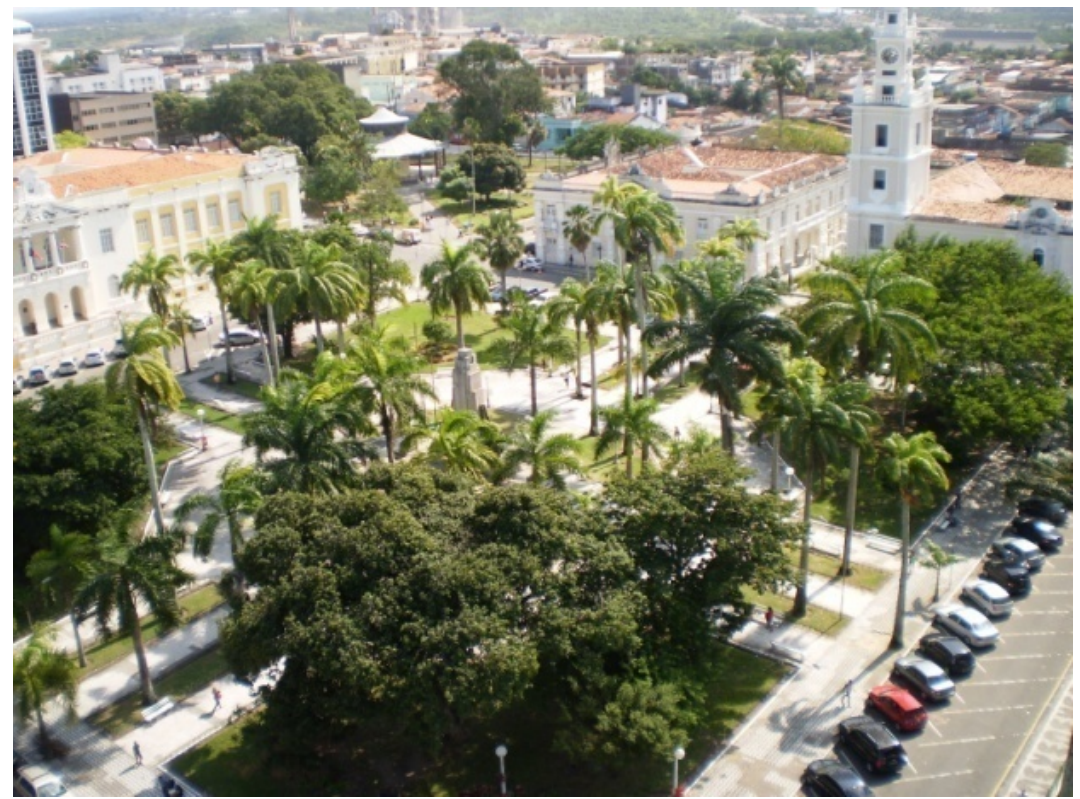

Figura 5 - Praça João Pessoa, 2011.

Fonte: Acervo da autora

No monumento (figuras $6,7,8$ e 9) as alegorias revelam sua cuidadosa idealização, cujo objetivo foi perpetuar a imagem de João Pessoa como bom administrador e herói. Neste sentido, de acordo com José Guilherme Abreu, há nas esculturas públicas sentidos intencionais, dos quais destaco dois o da rememoração e da devoção. Assim,

quando a intenção dominante é iconografar acontecimentos ou personalidades de um determinado tempo histórico, pela notoriedade e/ou relevância da sua ocorrência ou acção para a existência e a evolução colectivas, o sentido dominante é o da rememoração. Por outro, quando a intenção dominante é

10 Descrição de Humberto Cozzo, documento do Arquivo Privado de João Pessoa, IHGP.

URBANA, V.6, no 9, ago-dez, 2014 - Dossiê: Dimensões Simbólicas das Intervenções Urbanas CIEC/UNICAMP 
iconografar crenças ou entidades de um tempo sagrado, na transcendência encarnada da sua missão, o sentido dominante é o da devoção. (ABREU, 2003 p. 396) Destaques do autor.

Tais intenções são notáveis na concepção do monumento pelo artista e se ajusta perfeitamente com o sentimento que os partidários queriam passar.

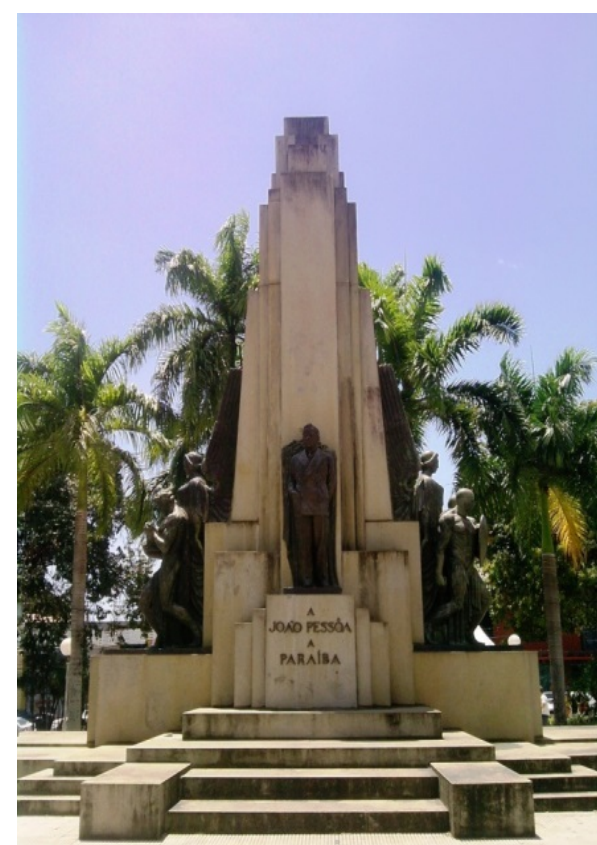

Figura 6 - Altar da Pátria

Fonte: Acervo da autora, 2012

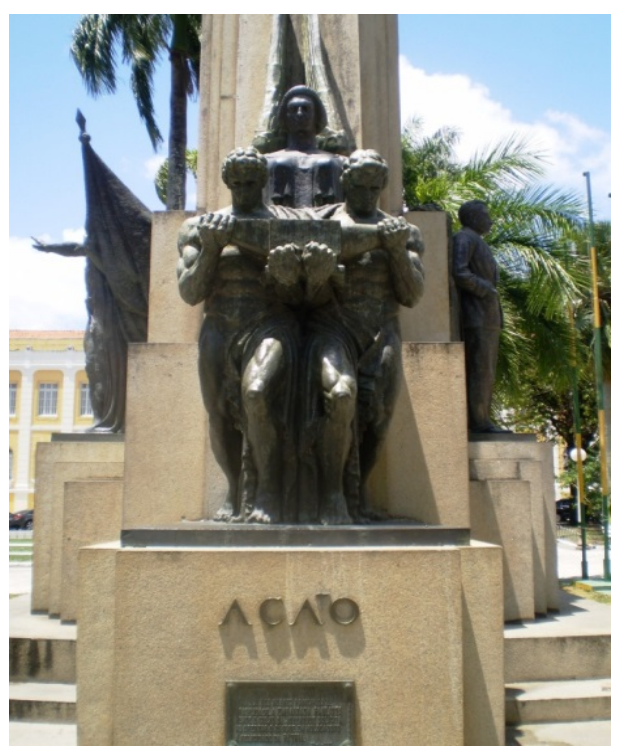

Figura 8 - Alegoria Ação

Fonte: Acervo da Autora, 2012

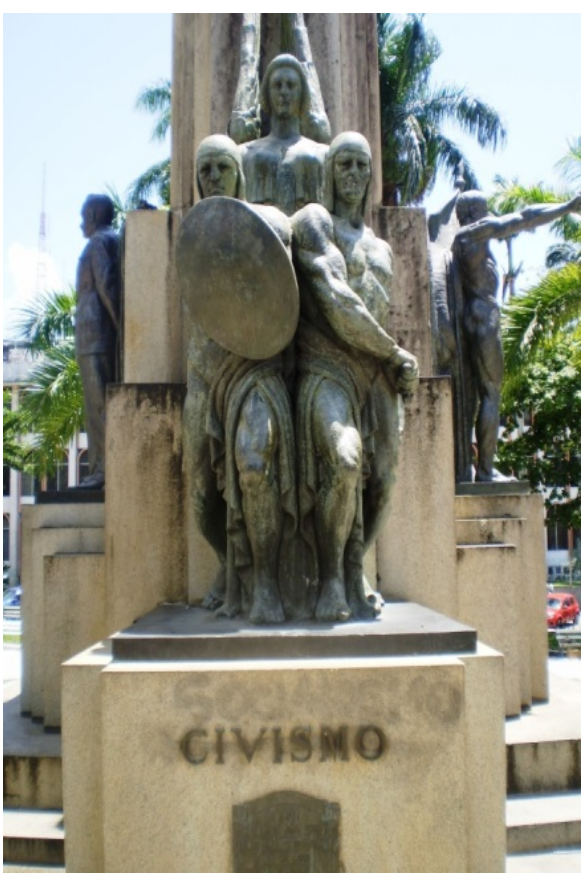

Figura 7 - Alegoria Civismo

Fonte: Acervo da Autora, 2012

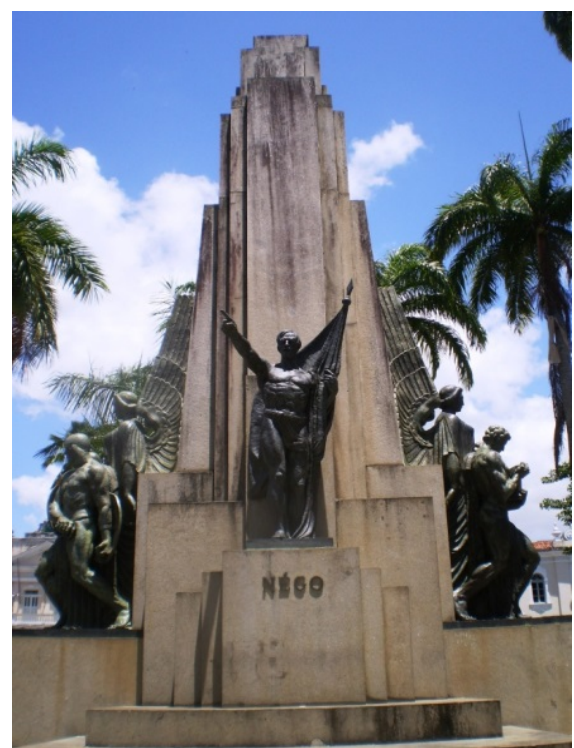

Figura 9 - Alegoria NEGO

Fonte: Acervo da Autora, 2012

URBANA, V.6, no 9, ago-dez, 2014 - Dossiê: Dimensões Simbólicas das Intervenções Urbanas CIEC/UNICAMP 
José Murilo de Carvalho (1990) nos lembra de que "não há regime que não promova o culto de seus heróis", esta foi a percepção no início da República, quando se buscou heroicizar os principais participantes de 15 de novembro, no qual Tiradentes foi a figura escolhida para se sagrar como herói republicano, através do apelo às tradições cristãs do povo (CARVALHO, 1990, p. 55-67). Como pudemos ver esta manobra permaneceu em voga e no contexto de 1930 o escolhido para herói,da nova fase republicana, foi João Pessoa. Comparado ao próprio Cristo, este tinha até um lugar especial para seu culto e sua memória, a praça.

No caso aqui estudado, vemos que o monumento a João Pessoa, atendeu então, a estas duas classes intencionais e foi utilizado para promover e legitimar a nova política que se instalava no país. No que diz respeito ao uso da religião e a política no Estado Novo, observou-se o uso da imagem do Cristo Crucificado, nas fábricas, para simbolizar as bênçãos ao trabalho. Característica presente nos regimes totalitários, que usam um "forte apego à sacralização do político como instrumento de dominação". (LENHARO, 1986, p. 170). Essa lógica se aplicou durante o Estado Novo a partir de 1937.

A sacralização da política visava dotar o Estado de uma legitimidade escorada em pressupostos mais nobres tirados da ordem política, funcionando como escudo religioso contra as oposições não debeladas. Da mesma forma os canais convencionais, alimentados pela religiosidade, podiam ser utilizados como condutores mais eficientes dos novos dispositivos de dominação que o poder engendrava (LENHARO, 1986, p.18).

A presença da Igreja nas ações movidas pelo Estado foi crucial para a construção da imagem de João Pessoa. Como podemos observar na fala do cônego Matias Freire. Em ocasião das bênçãos à pedra fundamental do monumento, se identifica claramente a intenção de fazer da praça um lugar de culto, o que legitima a sacralização desse espaço para a política. João Pessoa se tornou assim, ao mesmo tempo, herói e santo.

De acordo com Pierre Nora, um lugar de memória, deve atender a três sentidos: "material, simbólico e funcional, simultaneamente ou em graus diversos", que devem coexistir sempre. Ao exemplificar os três sentidos, Nora (1993, p. 21-22) nos diz que um depósito de arquivos, pode ser considerado um lugar de memória, "se a imaginação o investe de uma aura simbólica". Um lugar funcional, como um "manual de aula, um testamento, uma associação de antigos combatentes", precisa ser objeto de um ritual. E que o minuto de silêncio "exemplo extremo de uma URBANA, V.6, no 9, ago-dez, 2014 - Dossiê: Dimensões Simbólicas das Intervenções Urbanas CIEC/UNICAMP 
significação simbólica, é ao mesmo tempo o recorte material de uma unidade temporal" e que deve servir a "uma chamada concentrada de lembrança".

O monumento Altar da Pátria se ajusta aos três componentes, apontados por Pierre Nora. Assim, o sentido material encontra-se encarnado no monumento em si. 0 bronze foi transformado em depósito da memória e "investido de aura simbólica" através da imagem de João Pessoa e das alegorias presentes no monumento. 0 monumento foi concebido assim com o "sentido intencional da rememoração", já com a significação simbólica, pois ele corresponde a uma "chamada à lembrança" do herói João Pessoa. O que se agrega ao "sentido intencional da devoção"; funcional, por ser "objeto de um ritual" presente nas homenagens e celebrações póstumas na data de sua morte.

De acordo com Aires (2012, p. 90) de 1934 a 1945, na comemoração do dia 26 de julho, após a missa celebrada na catedral, seguia-se em romaria à Praça João Pessoa para o ritual da Guarda do Monumento, "cada cidadão permaneceria ao pé da estátua cerca de meia hora, em turmas previamente organizadas". Os interessados em participar do ritual eram convocados a se inscrever na sede do $A$ União, jornal oficial do estado. Neste sentido, a praça torna-se, então, o templo que abriga o altar.Ou seja, a presença do monumento na praça a transformou,de fato,num lugar investido de uma aura simbólica, cristalizando a memória da Revolução de 1930 e do seu mártir.

Conforme Pierre Nora (1993, p. 22) nos coloca que "a razão fundamental de ser de um lugar de memória é parar o tempo, é bloquear o trabalho do esquecimento, fixar um estado de coisas, imortalizar a morte, materializar o imaterial". Assim vemos que a "monumentalização" da praça extrapolou a própria ordem política que a gerou. Tanto o monumento a João Pessoa, como as esferas do poder ali instalado, chamou para o espaço da praça a teatralidade política e a presença de outros atores políticos/sociais que ultrapassaram os limites da própria ordem política que João Pessoa, em vida, buscou consolidar.

Com a instalação da Assembleia Legislativa, em 1975,a Praça João Pessoa teve seu caráter de espaço do poder, e da política, reforçado diante da presença do Tribunal de Justiça e do Palácio do Governo. É também conhecida como Praça dos Três Poderes. O referido espaço é utilizado para o exercício da democracia, sendo o lugar perfeito para manifestações e protestos de diversos segmentos sociais nas décadas seguintes e no momento atual. Acampamentos, comícios, término de 
passeatas, manifestações de diversas categorias profissionais e trabalhadores urbanos, além dos estudantes, tornaram-se comuns na Praça.

Diante de toda sua história, a Praça João Pessoa é incluída no roteiro das agências como ponto turístico a ser visitado (Figura 10). O estado atual da praça, no entanto, revela o descaso. Seus canteiros e passeios necessitam de cuidados e o monumento Altar da Pátria está com seus bancos de granito danificados (Figura 11). Além disso, o entorno imediato do monumento tem se transformado em banheiro público de moradores de rua no período noturno. Constatamos que, apesar da sua importância para a história política e urbana da cidade, a Praça João Pessoa só foi inserida recentemente nas políticas de revitalização do patrimônio e requalificação urbana da municipalidade. Contudo, uma ação concreta ainda não foi realizada.

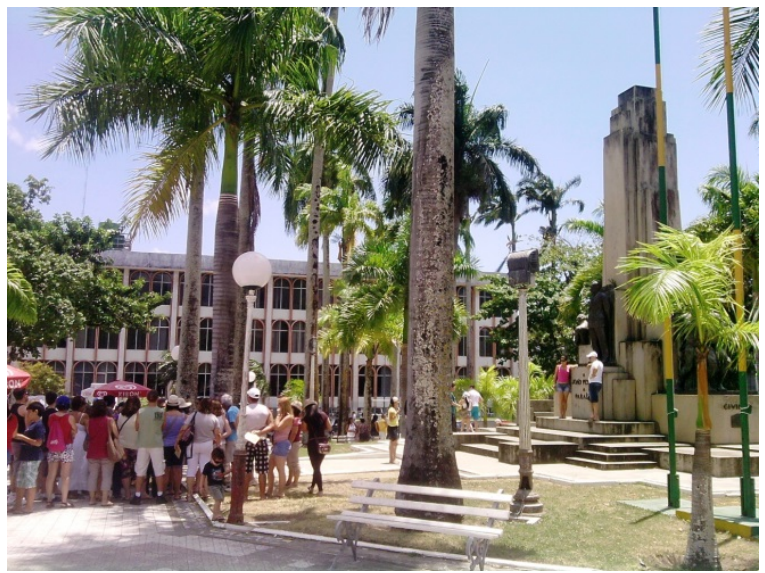

Figura 10 - Turistas na Praça João Pessoa.

Fonte: Acervo da Autora, 2012.

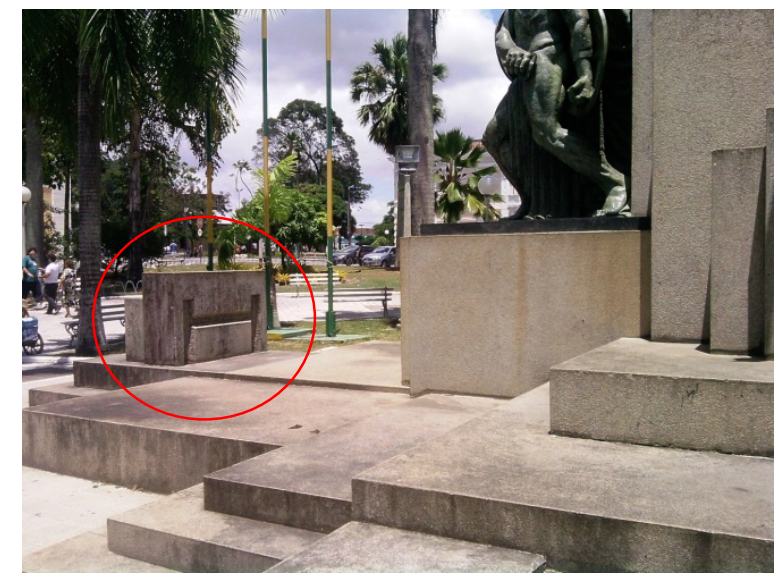

Figura 11 - Depredação do banco em granito do Monumento Altar da Pátria.

Fonte: Acervo da autora, 2012.

Assim, por guardar parte significativa da memória política e urbana da cidade de João Pessoa, a praça se configura como um marco histórico. É interessante notar que concepções renascentistas que agregaram o valor político-social, simbólico e artístico ainda estão presente na praça. As transformações pelas quais passou refletiram cada momento vivido e deixaram suas marcas na história da cidade. Esta praça pode ser tomada como emblemática, pois além das modificações na sua forma, também recebeu várias e diferentes denominações. Assim, conforme já mencionado, vemos que a forma e o uso da atual Praça João Pessoa são o resultado de um longo processo que se iniciou na segunda metade do século XIX e foi concluído no fim da Primeira República. Sua formação foi resultado das demandas urbanas nascidas de interesses religiosos, sociais e políticos.

URBANA, V.6, no 9, ago-dez, 2014 - Dossiê: Dimensões Simbólicas das Intervenções Urbanas CIEC/UNICAMP 


\section{Referências}

ABREU, José Guilherme (2003). Um modelo fenomenológico para a escultura pública.

Revista da Faculdade de Letras Ciências e Técnicas do Patrimônio. I Série vol. 2, pp. 385-418. Disponível em <ucp.academia.edu/ Acesso 15-Mar-12> Acesso em 16-mar-2011

AIRES, Luciano de Q (2006). Inventando Tradições, Construindo Memórias: A "Revolução de 1930" na Paraíba. 167 f. Dissertação (Mestrado em História). Universidade Federal da Paraíba.

CALDEIRA, Junia Marques (2007). A Praça Brasileira - trajetória de espaço urbano: origem e modernidade. 432 f. Tese (Doutorado em História) Departamento de História do Instituto de Filosofia e Ciências Humanas. Universidade Estadual de Campinas. UNICAMP.

CARVAlHO, José Murilo de (1990). A Formação das Almas: O Imaginário da República no Brasil. São Paulo: Companhia das Letras.

COlChete filho, Antonio (2008). Praça XV: projetos do espaço público. Rio de Janeiro: 7Letras.

COSTA, Cacilda T (2001). O sonho e a técnica: A arquitetura de Ferro no Brasil. São Paulo: EDUSP.

DE ANGELIS, Bruno D; CASTRO, Rosanda Miranda de; DE ANGELIS NETO, Generoso (maio 2004). Metodologia para Levantamento, cadastramento, diagnóstico e avaliação de praças no Brasil. Revista de Engenharia Civil da Universidade do Minho. Portugal: $\quad$ N. $20 . \quad$ Disponível em <http://www.civil.uminho.pt/cec/revista/Num20/Pag\%2057-70.pdf> Acesso em: 03Mar-12

FAUSTO, Boris (1981). A Revolução de 1930: historiografia e história. 7 ed. São Paulo: Brasiliense.

LENHARO, Alcir (1986). Sacralização da Política. Campinas: Papirus.

MARIANO, Serioja R. Cordeiro (2010).Signos em confronto?: O arcaico e o moderno na cidade de Princesa (PB) na década de 1920. João Pessoa: Editora Universitária da UFPB.

MARX, Murilo (1980). Cidade brasileira. São Paulo: Melhoramentos.

MUNIZ, Maria Águeda (2006). O plano diretor como instrumento dês Gestão da

Cidade: O caso da cidade de Fortaleza-CE. 397 f. Dissertação (Mestrado em Arquitetura e Urbanismo) Universidade Federal do Rio Grande do Norte.

URBANA, V.6, no 9, ago-dez, 2014 - Dossiê: Dimensões Simbólicas das Intervenções Urbanas CIEC/UNICAMP 
NORA, Pierre (1993). Entre Memória e História: a problemática dos lugares. In: Projeto História. n. 10

RAMOS, Leonard A (2006). A Praça João Pessoa: Passado e Presente. Monografia (Licenciatura em Geografia) Centro de Ciências Exatas e da Natureza. Universidade Federal da Paraíba

ROBBA, F. MACEDO, S. S (2002). Praças brasileiras. São Paulo: Edusp.

RODRIGUES, Inês Caminha Lopes (1978). A Revolta de Princesa: Uma contribuição ao estudo do Mandonismo Local - Paraíba (1930) João Pessoa: A União

STUCKeRT FILHO, G. Lyra (2004). Parahyba Capital em Fotos. V. I. João Pessoa: F\&A Gráfica e Editora.

URBANA, V.6, no 9, ago-dez, 2014 - Dossiê: Dimensões Simbólicas das Intervenções Urbanas CIEC/UNICAMP 